\title{
TI.93.1
}

\section{Reconnections Workshop Report}

- Text: internet2-reconnections-proceedings-200603.txt

\section{More Information}

\begin{tabular}{|l|l|}
\hline Repository ID & TI.93.1 \\
\hline Persistent URL & http://doi.org/10.26869/TI.93.1 \\
\hline Title & Reconnections Workshop Report \\
\hline Authors & \\
\hline Sponsor & SALSA \\
\hline Review & Legacy \\
\hline Status & March 29.2006 \\
\hline Publish Date & 10.26869/TI.93.1 \\
\hline DOI & \\
\hline Signature & No \\
\hline Deprecated & \\
\hline Future Review & \\
\hline Supersedes & Text \\
\hline Format & \\
\hline Related Docs & \\
\hline Development Location & \\
\hline IP Framework & \\
\hline Subject Tags & \\
\hline Notes & \\
\hline
\end{tabular}

